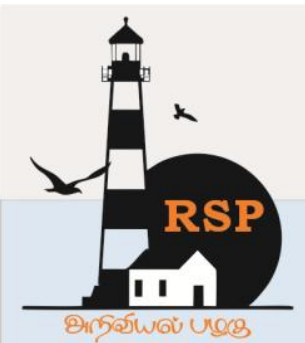

\title{
Statistical Analysis of Physico-Chemical Parameters
}

\section{Shaziya Mohammed Irfan Momin}

Assistant Professor, Department of Chemistry, G.M.Momin Women's College, Bhiwandi, Dist Thane, Maharashtra, India.

shaziyamomin79@gmail.com ${ }^{1}$

\begin{abstract}
Statistical analysis of some physico-chemical parameters like pH,Conductance,Total Solid,Total Alkalinity, Dissolved Oxygen, Biological Oxygen Demand,Chemical Oxygen Demand, Chloride And Total Hardness were done by Pearson Correlation Regression Analysis to find the correlation between concentration of two parameters with respect to each other.This is very significant way of analysis as it represent how does increase in one of the quality or physico-chemical parameter of water leads to increase or decrease in other parameter scientifically with correlation regression equation.
\end{abstract}

Keywords: Pearson Correlation Analysis, Various Physico-Chemical Parameters, Lake Water.

\section{Introduction}

Quantitatively the relationship maintained between two parameters by Pearson Correlation Analysis. It is important to remember that Pearson Correlation only provide information about the potency between the two properties. Fortunately researchers are usually interested in linear relationship between variables, so this is a very useful statistical test $(1,2,8)$.

As this research work is carried out to find the level of rise or decrease in the pollutants with respect to each other in the water from the very important and significant Varal Devi Lake lake. The water from this lake is mainly used for drinking purposes and for fishing. Varal Devi Lake [Varaala Lake] is an entertainment place for tourists as people enjoy boating. Fishes from the lake are eaten by majority of people in Bhiwandi city. As fish breed in water polluted with heavy metals it becomes harmful for human population who suffer from various diseases and disorders. It is therefore essential to determine the correlation between different physico-chemical parameters in order to ascertain the harmful effects of these pollutants on human health(7).

2. Methodology:

For locating the sampling point in a monitoring program is greatly dependent on the goals of the research activities. The sampling done from the following 3 sites of the Varal Devi lake of Bhiwandi city.

- Near Lake View Restaurant (Site S1).

-Kamat Ghar Gaon, Chandan Baug, Near Peace Park (Site S2).

-Phenapada, Phulegaon (Site S3).

The samples were taken in plastic containers of $1000.0 \mathrm{ml}$ volume capacity. Before sampling the 


\section{www.rspsciencehub.com}

new plastic container were cleaned with water followed by $1 \%$ Nitric Acid, repeatedly washed with deionised water and then completely dehydrated in an oven at 1030C.Samples were collected in the container carefully with no any air bubbles and labeled with date and time $(3,4) . \mathrm{pH}$, Conductance, Total Solid, Total Alkalinity, Dissolved Oxygen, Biological Oxygen Demand, Chemical Oxygen Demand, Chloride And Total Hardness were determined by classical or

\section{Volume 02 Issue 08 August 2020}

instrumental method. Quantitative results obtained are then analyzed statistically by using correlation analysis $(5,6)$.

Pearson Correlation Analysis has been calculated for water quality parameters by using the following formula.

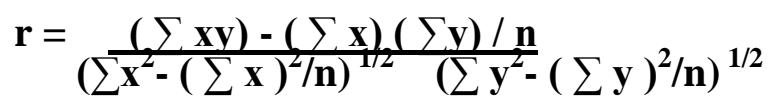

\section{Result and Discussion: Station 1 (S1) site:}

Table.1. Pearson Correlation Analysis:

\begin{tabular}{|c|c|c|c|c|c|c|c|c|c|}
\hline & $\mathrm{pH}$ & Conductance & TS & TA & DO & BOD & COD & Chloride & $\mathrm{TH}$ \\
\hline $\mathrm{pH}$ & 1 & & & & & & & & \\
\hline Conductance & -1 & 1 & & & & & & & \\
\hline $\mathrm{TS}$ & 0.5 & -0.5 & 1 & & & & & & \\
\hline TA & 1 & -1 & 0.5 & 1 & & & & & \\
\hline DO & -0.5 & 0.5 & -1 & -0.5 & 1 & & & & \\
\hline BOD & -0.5 & 0.5 & -1 & -0.5 & 1 & 1 & & & \\
\hline COD & -1 & 1 & -0.5 & -1 & 0.5 & 0.5 & 1 & & \\
\hline Chloride & $\begin{array}{c}- \\
0.982\end{array}$ & 0.98198 & $\begin{array}{c}- \\
0.3273\end{array}$ & -0.982 & 0.32734 & 0.32734 & 0.98198 & 1 & \\
\hline $\mathrm{TH}$ & 0.5 & -0.5 & 1 & 0.5 & -1 & -1 & -0.5 & -0.3273 & 1 \\
\hline
\end{tabular}


Station 2 (S2) site:

Table.2.Pearson Correlation Analysis:

\begin{tabular}{|c|c|c|c|c|c|c|c|c|c|}
\hline & $\mathrm{pH}$ & Conductance & $\begin{array}{c}\text { Total } \\
\text { Solid }\end{array}$ & $\begin{array}{c}\text { Total } \\
\text { Alkalinity }\end{array}$ & DO & BOD & COD & Chloride & TH \\
\hline $\mathrm{pH}$ & 1 & & & & & & & & \\
\hline Conductance & 1 & 1 & & & & & & & \\
\hline Total Solid & -1 & -1 & 1 & & & & & & \\
\hline Total & -1 & -1 & 1 & 1 & & & & & \\
\hline Alkalinity & -0.5 & -0.5 & -0.5 & 0.5 & 1 & & & & \\
\hline DO & -1 & -1 & 1 & 0.5 & 0.5 & 1 & & & \\
\hline BOD & 1 & 1 & -1 & -1 & -0.5 & -1 & 1 & & \\
\hline COD & -1 & -1 & 1 & 1 & 0.5 & 1 & -1 & 1 & \\
\hline Chloride & -1 & 1 & -1 & -1 & -0.5 & -1 & 1 & -1 & 1 \\
\hline TH & 1 & & & & & & & & \\
\hline
\end{tabular}

\section{Station 3 (S3) Site:}

Table.3. Pearson Correlation Analysis:

\begin{tabular}{|c|c|c|c|c|c|c|c|c|c|}
\hline & $\mathrm{pH}$ & Conductance & $\mathrm{T} \mathrm{S}$ & $\mathrm{T}$ A & DO & BOD & COD & Chloride & TH \\
\hline $\mathrm{pH}$ & 1 & & & & & & & & \\
\hline Conductance & 1 & 1 & & & & & & & \\
\hline Total Solid & 1 & 1 & 1 & & & & & & \\
\hline Total & -0.5 & -0.5 & -0.5 & 1 & & & & & \\
Alkalinity & & & & & & & & & \\
\hline DO & 1 & 1 & 1 & -0.5 & 1 & & & & \\
\hline BOD & 1 & 1 & 1 & -0.5 & 1 & 1 & & & \\
\hline COD & -1 & -1 & -1 & -0.5 & -1 & -1 & 1 & & \\
\hline Chloride & 1 & 1 & 1 & -0.5 & 1 & 1 & -1 & 1 & \\
\hline TH & 0.95688 & 0.95688 & 0.956 & - & 0.9568 & 0.9568 & -0.9569 & 0.95689 & 1 \\
& & & 88 & 0.7 & 9 & 9 & & & \\
\hline
\end{tabular}




\section{Conclusion:}

[Station 1 (S1) site]: Correlation Analysis Reveals That:

- pH:

pH correlates positively with Total Solids, Total Alkalinity and Total Hardness and inversely with conductance, DO, BOD, COD and Chloride. This indicates that with increase in the Total Solid, TA and TH, pH increases. With increase in Conductance, Dissolved Oxygen, BOD, COD and Chloride, the value of $\mathrm{pH}$ decreases.

- Conductance:

Conductance correlates positively with DO, BOD, COD,Chloride and inversely with Total Solid, Total Alkalinity and Total Hardness.

- Total Solids:

Total Solid correlates positively with Total Hardness and Total Alkalinity and inversely with DO, BOD, COD and Chloride.

- Total Alkalinity:

TA correlates positively with Total Hardness and inversely with DO, BOD, COD, Chloride and TH.

- Dissolved Oxygen:

Dissolved Oxygen correlates positively with BOD, COD and Chloride and inversely with Total Hardness.

- Biochemical Oxygen Demand:

BOD relates COD, Chloride and not with TH.

- Chemical Oxygen Demand:

COD correlates positively with Chloride and negatively with Total Hardness.

- Chloride:

Chloride correlates negatively with Total Hardness.

[Station 2 (S2) site]:Correlation Analysis Reveals That:

- $\mathbf{p H}$

pH correlates positively with Conductance, Chemical Oxygen Demand and Total Hardness and inversely with TS, Alkalinity, DO, Biological OD, Chloride. This indicates that with increase in the Conductance, Chemical Oxygen Demand and Total Hardness, pH increases.

- Conductance:

Conductance correlates positively with $\mathrm{TH}$, COD and inversely with Total Solid, Total Alkalinity, DO, Biological Oxygen Demand and Chloride.

- Total Solids:

Total Solids correlates positively with TA, BOD and Chloride and inversely with DO, COD and TH.

- Total Alkalinity:

Total Alkalinity correlates positively with Total Hardness and inversely with DO, BOD, COD, Chloride and TH.

\section{- Dissolved Oxygen:}

DO correlate positively with BOD and Chloride and inversely with COD and TH.

- Biochemical Oxygen Demand:

BOD relates directly to Chloride and inversely with COD and TH.

- Chemical Oxygen Demand:

COD positively relates with Total Hardness and negatively with Chloride.

- Chloride:

Chloride correlates negatively with Total Hardness.

[Station 3 (S3) Site]: Correlation Analysis

\section{Reveals That:}

- pH:

pH correlates positively with Conductance, Total Solid, DO,BOD, Chloride and $\mathrm{TH}$ and inversely with COD and TA.

\section{- Conductance:}

Conductance correlates positively with Total Solid, DO, BOD, Chloride and $\mathrm{TH}$ and inversely with COD and TA.

\section{- Total Solids:}

Total Solids correlates positively with DO,BOD and Chloride and inversely with TA and COD.

- Total Alkalinity:

Total Alkalinity correlates inversely with 
www.rspsciencehub.com

DO,BOD, COD, Chloride and TA.

- Dissolved Oxygen:

DO correlate positively with BOD, Chloride and Total Hardness and inversely with COD.

\section{- Biochemical Oxygen Demand:}

BOD correlates positively with Chloride and Total Hardness and negatively with COD.

\section{- Chemical Oxygen Demand:}

COD correlates positively with Chloride and negatively with Total Hardness.

\section{- Chloride:}

Chloride correlates positively with Total Hardness.

\section{References:}

[1] P.S. Sindhu, Environmental Chemistry, New Age International Publisher, Chapter Water Pollution, 54-59.

[2] N. Roger. Reeve, Environmental Analysis, John Wiley and Sons Publication

[3] Godghate A.G., Sawant.R.S. and Jadhav.S.D.,(2013), An Evaluation of Physico-chemical Parameters to Assess Borewell Water Quality from Madyal and Vadgaon Villages of Kagal Tahsil, MS, India, International Research Journal of Environment Sciences, 2(5), 95-97.

[4] Ehiagbonare. J. E. and Ogunrinde.Y. O.,(2010), Physico-chemical analysis of fish pond water in Okada and its environs, Nigeria, African Journal of Biotechnology,9(36), 5922-5928.

[5] A. K. De, Environmental Chemistry, International (P) Ltd, Publishers: Fifth edition New Age.

[6] Andrew D.E.,AWWA Chair, Lenore .S.Clesceri, WEF, EugeneW.Rice, APHA, Arnold E.Greenberg.Std methods for Examination of Water and waste water, APHA, AWWA,Water Environment Federation ( 2005) ( ${ }^{21 s t}$ ed.).

[7] Adefemi S.O, Awokunmi E.E,(2010), Determination of water parameters and heavy metals in the water sample from Itaogbolu, J of Env.Sci \& Tech,4(3),145-148.
Volume 02 Issue 08 August 2020

[8] Skoog. Holler. Nieman, Principles of Instrumental Analysis,: Fifth Edition 